\title{
Enumeration of Benzenoid and Coronoid Hydrocarbons
}

A. T. Balaban ${ }^{\text {a }}$, J. Brunvoll ${ }^{\text {b }}$, J. Cioslowski ${ }^{\text {c }}$, B. N. Cyvin ${ }^{\text {b }}$,

S. J. Cyvin ${ }^{\text {b }}$, I. Gutman ${ }^{\text {d }}$, He Wenchen ${ }^{\mathrm{e}}$, He Wenjie ${ }^{\mathrm{f}}$, J. V. Knop ${ }^{\mathrm{g}}$, M. Kovačević ${ }^{\mathrm{h}}$,

W. R. Müller ${ }^{\mathrm{g}}$, K. Szymanski ${ }^{\mathrm{g}}$, R. Tošić ${ }^{\mathrm{h}}$, and N. Trinajstić ${ }^{\mathrm{i}}$

a The Polytechnic, Bucharest, Rumania.

b The University of Trondheim, Norway.

c Georgetown University, Washington D.C., USA.

d University of Kragujevac, Yugoslavia.

e Hebei Chemical Engineering Institute, Shijiazhuang, PR China.

Hebei Academy of Sciences, Shijiazhuang, PR China.

$g$ Computer Centre, The University of Düsseldorf, FR Germany.

h University of Novi Sad, Yugoslavia.

i The Rugjer Bošković Institute, Zagreb, Yugoslavia.

Z. Naturforsch. 42 a, 863-870 (1987); received April 7, 1987

This is a report on the present status of computer-aided enumeration and classification of benzenoids and coronoids (polyhexes). The existing data from previous works are displayed in comprehensive tables. Numerous data from papers in press are included, as well as original contributions.

\section{Introduction}

The problem of "cell-growth" is a classical problem in mathematics [1-5]. When applied to hexagonal "animals" it has relevance to the studies of benzenoid (polycyclic aromatic) hydrocarbons, especially to their enumeration [6-27]. The research field is rapidly expanding, as is documented by the numerous papers in press or just appeared [28-34].

In works of this type it is important to define precisely the classes of systems which are subjected to enumeration. Here a benzenoid is defined in consistence with a review [35] and a book [36]. It is a planar system of identical regular hexagons, which are simply connected. The last restriction is released in the definition of coronoids. In those systems (also called "true" circulenes) a hole is recognized, which should have a size of at least two hexagons. Multiple coronoids with more than one hole are possible. It is emphasized that we adher to the definitions which exclude helicene derivatives and similar systems.

A catacondensed system (benzenoid [35] or coronoid [28]) does not possess any vertex belonging to three hexagons $[3,35-40]$. The feature is manifested by the absence of triangles in the dualist

Reprint requests to Prof. Dr. S. J. Cyvin, Division of Physical Chemistry, The University of Trondheim, N-7034 Trondheim-NTH, Norway. graph. All other systems are referred to as pericondensed. A system is non-Kekuléan when it does not possess any Kekulé structure; in the opposite case it is called Kekulean. All catacondensed systems are known to be Kekuléan. Alternative designations for catacondensed benzenoids and pericondensed benzenoids are catafusenes and perifusenes, respectively.

The term polyhex seems to be a suitable designation for benzenoids and coronoids together.

In general it is noted that no terminology in this area has been established as a prevailing standard at present.

In the present work we summarize some previous results on enumeration of benzenoids and coronoids. Also new results are reported, where the ranges of computation have been extended with regard to the $h$ value. Here $h$ denotes the number of hexagons of a system.

The footnotes to tables (see below) are supposed to give the credit of priority to the different researchers. The quoted numbers are either found explicitly in the cited references or obtained simply by additions or subtraction of published numbers. Still the quotations do not give full justice to all researchers which have developed this field because of the special definitions of benzenoids and coronoids adherred to here. These conventions discriminate in particular the important works of 
Harary and Read [3] and of Lunnon [4]. These authors have included helicenes not covered by the definitions of the present work. Similarly the works of Balaban and Harary [6] and Balaban [7, 8] are discriminated due to the inclusion of helicenes.

In the present report the number of hexagons, $h$, is the leading parameter. As a consequence it makes the extensive works of Dias [13, 14, 17-19, 22] fall outside the present scope. This researcher concentrated upon the chemical isomerism, which is reflected by the chemical formula $\mathrm{C}_{n} \mathrm{H}_{s}$. For polyhexes $n$ is the total number of vertices and $s$ the number of vertices of second degree. The works of Cyvin [24] and Cyvin et al. [26, 31, 32], where the benzenoids are enumerated according to their Kekulé structure counts, fall also outside the scope of the present report.

\section{Benzenoids}

\section{Catacondensed Benzenoids}

Table 1 shows the results of enumeration for catacondensed benzenoids (catafusenes). The unbranched systems are classified according to their symmetries into [6]: $a$ acenes (linear): $\mathrm{D}_{6 h}$ for $h=1$, otherwise $\mathrm{D}_{2 h}$,

$m$ mirror-symmetrical, $\mathrm{C}_{2 r}$;

$c$ centrosymmetrical, $\mathrm{C}_{2 h}$;

$u$ unsymmetrical, $\mathrm{C}_{s}$.

\section{Pericondensed Benzenoids}

Table 2 shows the results of enumeration for pericondensed benzenoids (perifusenes). All nonKekuléans $(o)$ are pericondensed. The Kekuléan pericondensed systems are divided into:

$n p$ normal pericondensed;

$e$ essentially disconnected [41].

The latter systems (e) possess edges which have fixed bonds (simple or double) in all Kekulé structures. All other Kekuléans are referred to as normal $[23,25]$.

\section{Coronoids (Single)}

Multiple coronoids exist, the smallest one having $h=13$ [14]. They are not counted in this report.

Table 1. Numbers of catacondensed benzenoids (catafusenes).

\begin{tabular}{|c|c|c|c|c|c|c|c|}
\hline \multirow[t]{2}{*}{$h$} & \multicolumn{4}{|c|}{ Unbranched } & \multirow{2}{*}{$\begin{array}{l}\text { Total } \\
\text { unbranched }\end{array}$} & \multirow[t]{2}{*}{ Branched } & \multirow{2}{*}{$\begin{array}{l}\text { Total } \\
\text { catacondensed }\end{array}$} \\
\hline & $a$ & $m$ & $c$ & u & & & \\
\hline 1 & $1^{\mathrm{a}}$ & 0 & 0 & 0 & $1^{\mathrm{a}}$ & 0 & $1^{\mathrm{a}}$ \\
\hline 2 & $1^{\mathrm{a}}$ & 0 & 0 & 0 & $1^{\mathrm{a}}$ & 0 & $1^{\mathrm{a}}$ \\
\hline 3 & $1^{\mathrm{a}}$ & $1^{\mathrm{a}}$ & 0 & 0 & $2^{\mathrm{a}}$ & 0 & $2^{\mathrm{a}}$ \\
\hline 4 & $1^{\mathrm{a}}$ & $1^{\mathrm{a}}$ & $1^{\mathrm{a}}$ & $1^{\mathrm{a}}$ & $4^{\mathrm{a}}$ & $1^{\mathrm{a}}$ & $5^{a}$ \\
\hline 5 & $1^{\mathrm{a}}$ & $4^{\mathrm{a}}$ & $1^{\mathrm{a}}$ & $4^{\mathrm{a}}$ & $10^{\mathrm{a}}$ & $2^{\mathrm{a}}$ & $12^{\mathrm{a}}$ \\
\hline 6 & $1^{\mathrm{a}}$ & $3^{b}$ & $4^{\mathrm{a}}$ & $16^{\mathrm{a}}$ & $24^{\mathrm{c}}$ & $12^{\mathrm{c}}$ & $36^{\mathrm{d}}$ \\
\hline 7 & $1^{\mathrm{a}}$ & $12^{b}$ & $4^{\mathrm{a}}$ & $50^{b}$ & $67^{c}$ & $51^{\mathrm{c}}$ & $118^{\mathrm{d}}$ \\
\hline 8 & $1^{\mathrm{a}}$ & $10^{\mathrm{b}}$ & $13^{a}$ & $158^{\mathrm{b}}$ & $182^{c}$ & $229^{c}$ & $411^{\mathrm{d}}$ \\
\hline 9 & $1^{b}$ & $34^{\mathrm{b}}$ & $13^{b}$ & $472^{b}$ & $520^{\mathrm{b}, \mathrm{e}}$ & $969^{\mathrm{b}, \mathrm{e}}$ & $1489^{\mathrm{d}}$ \\
\hline 10 & $1^{\mathrm{b}}$ & $28^{\mathrm{b}}$ & $39^{\mathrm{b}}$ & 1406 & 1474 & 4098 & $5572^{d}$ \\
\hline 11 & $1^{\mathrm{b}}$ & $97^{b}$ & $39^{b}$ & 4111 & 4248 & 16867 & $21115^{f}$ \\
\hline 12 & $1^{b}$ & $81^{\mathrm{b}}$ & $116^{b}$ & 11998 & 12196 & $\dagger$ & $\dagger$ \\
\hline 13 & 1 & 271 & 115 & 34781 & 35168 & $\dagger$ & $\dagger$ \\
\hline 14 & 1 & 226 & 339 & 100660 & 101226 & $\dagger$ & $\dagger$ \\
\hline 15 & 1 & 764 & 336 & 290464 & 291565 & $\dagger$ & $\dagger$ \\
\hline 16 & 1 & 638 & 988 & 837137 & 838764 & $\dagger$ & $\dagger$ \\
\hline 17 & 1 & 2141 & 977 & 2408914 & 2412033 & $\dagger$ & $\dagger$ \\
\hline 18 & 1 & 1787 & 2866 & 6925100 & 6929754 & $\dagger$ & $\dagger$ \\
\hline 19 & 1 & 6025 & 2832 & 19888057 & 19896915 & $\dagger$ & $\dagger$ \\
\hline 20 & 1 & 5030 & 8298 & 57071610 & 57084939 & $\dagger$ & $\dagger$ \\
\hline
\end{tabular}

a Balaban and Harary [6]. $-{ }^{\mathrm{b}}$ Brunvoll, Cyvin, and Cyvin [29]. $-{ }^{\mathrm{c}}$ He and He [20]. $-{ }^{\mathrm{d}}$ Knop, Szymanski, Jeričević, and Trinajstić [11]. $-{ }^{\mathrm{e}} \mathrm{He}$ and He [33]. $-{ }^{\mathrm{f}}$ Stojmenović, Tošić, and Doroslovački [34]. $-{ }^{\dagger}$ Unknown. 
Table 2. Numbers of pericondensed benzenoids (perifusenes).

\begin{tabular}{rrrrrr}
\hline$h$ & Kekuléan & \multicolumn{2}{c}{$\begin{array}{l}\text { Total } \\
\text { pericon- } \\
\text { densed } \\
\text { Kekuléan* }\end{array}$} \\
\cline { 2 - 6 } & \multicolumn{1}{c}{$e$} & $\begin{array}{l}\text { Non- } \\
\text { Kekuléan }\end{array}$ & $\begin{array}{l}\text { Total } \\
\text { pericon- } \\
\text { densed } * *\end{array}$ \\
\hline 3 & 0 & 0 & 0 & $1^{\mathrm{a}}$ & 1 \\
4 & $1^{\mathrm{a}}$ & 0 & 1 & $1^{\mathrm{a}}$ & 2 \\
5 & $2^{\mathrm{b}}$ & $1^{\mathrm{b}}$ & 3 & $7^{\mathrm{a}}$ & 10 \\
6 & $12^{\mathrm{b}}$ & $3^{\mathrm{b}}$ & 15 & $30^{\mathrm{a}}$ & 45 \\
7 & $49^{\mathrm{b}}$ & $23^{\mathrm{b}}$ & 72 & $141^{\mathrm{c}}$ & 213 \\
8 & $232^{\mathrm{b}}$ & $121^{\mathrm{b}}$ & 353 & $671^{\mathrm{c}}$ & 1024 \\
9 & $1042^{\mathrm{b}}$ & $692^{\mathrm{b}}$ & 1734 & $3282^{\mathrm{b}}$ & 5016 \\
10 & $4803^{\mathrm{d}}$ & 3732 & 8535 & 15979 & 24514 \\
11 & $21804^{\mathrm{d}}$ & 19960 & 41764 & 78350 & 120114 \\
\hline
\end{tabular}

* The sums of numbers in the two first columns.

** Obtained as differences from published data (Grand total - Total catacondensed).

a Balaban and Harary [6]. - ${ }^{\mathrm{b}}$ Brunvoll, Cyvin, and Cyvin [29]. $-{ }^{c} \mathrm{He}$ and $\mathrm{He}[20] .{ }^{\mathrm{d}}$ Cyvin, Brunvoll, and Cyvin [32].

Table 3. Numbers of catacondensed coronoids.

\begin{tabular}{rcrr}
\hline$h$ & $\begin{array}{l}\text { Primitive } \\
\text { (unbranched) }\end{array}$ & $\begin{array}{l}\text { Annelated } \\
\text { (branched) }\end{array}$ & $\begin{array}{l}\text { Total } \\
\text { catacondensed * }\end{array}$ \\
\hline 8 & $1^{\mathrm{a}}$ & 0 & 1 \\
9 & $1^{\mathrm{a}}$ & $2^{\mathrm{a}}$ & 3 \\
10 & $3^{\mathrm{a}}$ & $12^{\mathrm{a}}$ & 15 \\
11 & $2^{\mathrm{a}}$ & $60^{\mathrm{a}}$ & 62 \\
12 & $11^{\mathrm{a}}$ & 301 & 312 \\
13 & $12^{\mathrm{a}}$ & 1423 & 1435 \\
14 & $40^{\mathrm{a}}$ & $\dagger$ & $\dagger$ \\
15 & 68 & $\dagger$ & $\dagger$ \\
16 & 192 & $\dagger$ & $\dagger$ \\
17 & 395 & $\dagger$ & $\dagger$ \\
18 & 1061 & $\dagger$ & $\dagger$ \\
19 & 2432 & $\dagger$ & $\dagger$ \\
20 & 6318 & $\dagger$ & $\dagger$ \\
\hline
\end{tabular}

* The sums of numbers of the two first columns.

a Brunvoll, Cyvin, and Cyvin [28]. - ${ }^{\dagger}$ Unknown.

Table 4. Numbers of pericondensed coronoids.

\begin{tabular}{|c|c|c|c|c|c|}
\hline \multirow[t]{2}{*}{$h$} & \multicolumn{2}{|c|}{ Kekuléan } & \multirow{2}{*}{$\begin{array}{l}\text { Total peri- } \\
\text { condensed } \\
\text { Kekuléan* }\end{array}$} & \multirow{2}{*}{$\begin{array}{l}\text { Non- } \\
\text { Kekuléan }\end{array}$} & \multirow{2}{*}{$\begin{array}{l}\text { Total } \\
\text { pericon- } \\
\text { densed } * *\end{array}$} \\
\hline & $n p$ & $e$ & & & \\
\hline 9 & 0 & 0 & 0 & $2^{\mathrm{a}}$ & $2^{\mathrm{a}}$ \\
\hline 10 & $9^{\mathrm{a}}$ & 0 & 9 & $19^{\mathrm{a}}$ & $28^{\mathrm{a}}$ \\
\hline & $64^{\mathrm{a}}$ & $2^{\mathrm{a}}$ & 66 & $155^{\mathrm{a}}$ & $221^{\mathrm{a}}$ \\
\hline 12 & 508 & 34 & 542 & $1100^{\mathrm{a}}$ & 1642 \\
\hline
\end{tabular}

* The sums of numbers in the two first columns.

** Sum Pericondensed Kekuléan + Non-Kekuléan.

a Brunvoll, Cyvin, and Cyvin [28].
Table 3 shows the numbers of catacondensed coronoids. Primitive [28] systems are defined as consisting of one single circular chain. The other catacondensed systems have at least one branching hexagon and are sometimes referred to as annelated.

Table 4 shows the number of pericondensed coronoids. The designations $n p$ and $e$ refer to normal pericondensed and essentially disconnected systems in analogy with the benzenoids (see above, especially Table 2 ).

\section{The "neo" Classification}

The usefulness of a distinction between normal $(n)$ and essentially disconnected (e) benzenoids or coronoids among the Kekuléan systems has been pointed out previously [24, 26, 29]. Here the normal benzenoids or coronoids refer to the catacondensed systems together with the normal pericondensed. The inclusion of non-Kekuléan systems ( $o$ ) gives the grand total $(n+e+o)$. The concept neo classification refers to the $n, e$ and $o$ classes. The different numbers of the benzenoids and coronoids (in parentheses) within this classification are summarized in Table 5.

\section{More Special Classifications}

\section{Symmetry}

The classification of unbranched catacondensed benzenoids according to symmetry was first undertaken by Balaban and Harary [6], and pursued by Brunvoll et al. [29]; cf. Table 1. It has been pointed out that the benzenoids in general can belong to one of the eight symmetries [42]: $\mathrm{D}_{6 h}, \mathrm{C}_{6 h}, \mathrm{D}_{3 h}, \mathrm{C}_{3 h}$, $\mathrm{D}_{2 h}, \mathrm{C}_{2 h}, \mathrm{C}_{2 v}$ or $\mathrm{C}_{s}$. The same is the case for coronoids. Table 6 summarizes the distribution into the different symmetries for all benzenoids (also pericondensed and branched catacondensed) and coronoids; the latter results are given in parentheses.

\section{$\triangle$ Values}

The positive integer $\Delta$ is an important parameter for benzenoids and coronoids. It is defined as the absolute magnitude of the difference between the numbers of black and white vertices, referring to 
Table 5. The "neo" classification for benzenoids and coronoids (numbers in parentheses).

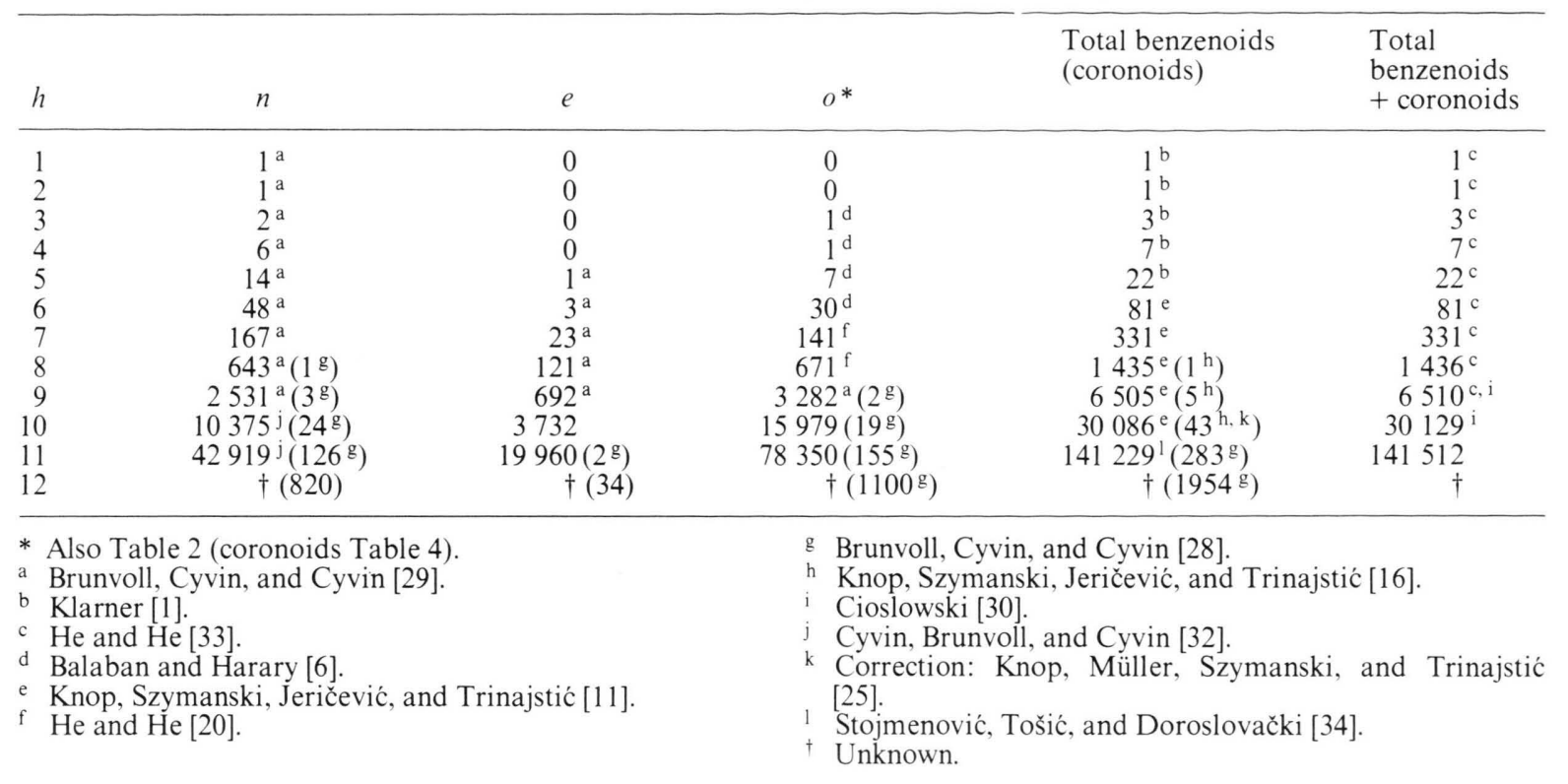

Table 6. Numbers of benzenoids and coronoids (in parentheses) of different symmetries.

\begin{tabular}{|c|c|c|c|c|c|c|c|c|}
\hline$h$ & $D_{6 h}$ & $C_{6 h}$ & $D_{3 h}$ & $C_{3 h}$ & $D_{2 h}$ & $C_{2 h}$ & $C_{2 v}$ & $C_{s}$ \\
\hline 1 & 1 & 0 & 0 & 0 & 0 & 0 & 0 & 0 \\
\hline 2 & 0 & 0 & 0 & 0 & 1 & 0 & 0 & 0 \\
\hline 3 & 0 & 0 & 1 & 0 & 1 & 0 & 1 & 0 \\
\hline 4 & 0 & 0 & 1 & 0 & 2 & 1 & 1 & 2 \\
\hline 5 & 0 & 0 & 0 & 0 & 2 & 1 & 9 & 10 \\
\hline 6 & 0 & 0 & 1 & 1 & 3 & 7 & 12 & 57 \\
\hline 7 & 1 & 0 & 1 & 1 & 3 & 7 & 39 & 279 \\
\hline 8 & 0 & 0 & 0 & 0 & $6(1)$ & 35 & 61 & 1333 \\
\hline 9 & 0 & 0 & $1(1)$ & 5 & $7(0)$ & 36 & $178(1)$ & 6278 (3) \\
\hline 10 & 0 & 0 & $4(0)$ & 5 & $11(3)$ & $169(3)$ & $274(9)$ & $29623(28)$ \\
\hline 11 & 0 & 0 & $0(0)$ & 0 & $14(0)$ & $177(0)$ & $796(24)$ & $140242(259)$ \\
\hline 12 & $0(1)$ & 0 & $3(3)$ & $21(2)$ & $21(10)$ & $807(25)$ & $\dagger(79)$ & $\dagger(1834)$ \\
\hline 13 & $2(0)$ & 0 & $4(0)$ & $26(0)$ & $23(0)$ & $859(0)$ & $\dagger(185)$ & $\dagger(\dagger)$ \\
\hline 14 & $0(0)$ & 0 & $0(0)$ & $0(0)$ & $41(\dagger)$ & $\dagger(\dagger)$ & $\dagger(\dagger)$ & $\dagger(\dagger)$ \\
\hline 15 & $0(0)$ & 0 & $3(9)$ & 95 (17) & $50(0)$ & $\dagger(0)$ & $\dagger(\dagger)$ & $\dagger(\dagger)$ \\
\hline 16 & $0(0)$ & 0 & $12(0)$ & $118(0)$ & $80(\dagger)$ & $\dagger(\dagger)$ & $\dagger(\dagger)$ & $\dagger(\dagger)$ \\
\hline 17 & $0(0)$ & 0 & $0(0)$ & $0(0)$ & $94(0)$ & $\dagger(0)$ & $\dagger(\dagger)$ & $\dagger(\dagger)$ \\
\hline 18 & $0(3)$ & $0(1)$ & $6(23)$ & $423(102)$ & $156(\dagger)$ & $\dagger(\dagger)$ & $\dagger(\dagger)$ & $\dagger(\dagger)$ \\
\hline 19 & $2(0)$ & $2(0)$ & $19(0)$ & $543(0)$ & $189(0)$ & $\dagger(0)$ & $\dagger(\dagger)$ & $\dagger(\dagger)$ \\
\hline 20 & $0(0)$ & $0(0)$ & $0(0)$ & $0(0)$ & $310(\dagger)$ & $\dagger(\dagger)$ & $\dagger(\dagger)$ & $\dagger(\dagger)$ \\
\hline
\end{tabular}

\footnotetext{
† Unknown.
}

the coloring of vertices ("black and white" is synonymous with "starred and unstarred") [37, 40]. This number ( $\Delta)$ is also equal to the absolute magnitude of the difference between the numbers of valleys and peaks [43, 44]. Furthermore, $\Delta$ is also equal to the absolute magnitude of the difference between the numbers of upright and upset triangles $[20,45]$ in the dualist graph [6]. It is long known that all Kekuléan systems have $\Delta=0$, and that this is not a sufficient condition [37]. Non-Kekuléan benzenoids and coronoids with $\Delta=0$ exist; benzenoids when $h \geqq 11$ [37] and coronoids when $h \geqq 15$ [28]. They are called concealed non-Kekuléans [28, 44]. The others $(\Delta>0)$ are referred to as obvious nonKekuléan [44]. Table 7 shows the distribution of $\Delta$ values for all benzenoids (and coronoids). 
Table 7. Numbers of benzenoids and coronoids (in parentheses) with different $\Delta$ values.

\begin{tabular}{cccccc}
\hline$h$ & $\Delta=0^{*}$ & $\Delta=1$ & $\Delta=2$ & $\Delta=3$ & $\Delta=4$ \\
\hline 1 & 1 & 0 & 0 & 0 & 0 \\
2 & 1 & 0 & 0 & 0 & 0 \\
3 & 2 & $1^{\mathrm{a}}$ & 0 & 0 & 0 \\
4 & 6 & $1^{\mathrm{a}}$ & 0 & 0 & 0 \\
5 & 15 & $7^{\mathrm{a}}$ & 0 & 0 & 0 \\
6 & 51 & $28^{\mathrm{a}}$ & $2^{\mathrm{a}}$ & 0 & 0 \\
7 & 190 & $134^{\mathrm{a}}$ & $7^{\mathrm{a}}$ & 0 & 0 \\
8 & $764\left(1^{\mathrm{b}}\right)$ & $619^{\mathrm{a}}$ & $52^{\mathrm{a}}$ & 0 & 0 \\
9 & $3223\left(3^{\mathrm{b}}\right)$ & $2957\left(2^{\mathrm{b}}\right)$ & 322 & 3 & 0 \\
10 & $14107\left(24^{\mathrm{b}}\right)$ & $14024\left(16^{\mathrm{b}}\right)$ & $1916\left(3^{\mathrm{b}}\right)$ & 39 & 0 \\
11 & $62887\left(128^{\mathrm{b}}\right)$ & $67046\left(131^{\mathrm{b}}\right)$ & $10922\left(23^{\mathrm{b}}\right)$ & $374\left(1^{\mathrm{b}}\right)$ & 0 \\
12 & $+\left(854^{\mathrm{b}}\right)$ & $\dagger\left(906^{\mathrm{b}}\right)$ & $+\left(182^{\mathrm{b}}\right)$ & $+\left(12^{\mathrm{b}}\right)$ & 14 \\
\hline
\end{tabular}

* For benzenoids when $h \leqq 10$ : All Kekuléan, viz. catacondensed (Table 1) $+n p+e$ (Table 2). All coronoids when $h \leqq 14$ are Kekuléan, viz. catacondensed (Table 3 ) $+n p+e$ (Table 4).

a Brunvoll, Cyvin, and Cyvin [29]. - b Brunvoll, Cyvin, and Cyvin [28]. $-{ }^{\dagger}$ Unknown.

It was demonstrated by an inductive reasoning that the maximal $\Delta$ value for a benzenoid is

$$
\Delta_{\max }=\left[\frac{h}{3}\right],
$$

where $[x]$ is used to designate the largest integer smaller than or equal to $x$.

\section{Numbers of Internal and External Vertices}

The computer program of Knop and Trinajstic with collaborators $[11,12,16,21]$ is based on the fact that a benzenoid is uniquely defined by its perimeter. For the purpose of identification these authors devised a boundary code given in terms of a six-letter alphabet, actually consisting of a sequence of integers. Basically the same idea was first used by Balaban [46], and was employed with modifications by Doroslovački and Tošić with collaborators $[15,23,34]$.

Table 8 includes the data from Knop et al. [11] concerning the classification of benzenoids according to their number of internal vertices, say $n_{\mathrm{i}}$.

Stojmenović et al. [34] performed a classification according to the length of the perimeter. Actually their material contains the enumeration of all benzenoids with the perimeter length up to 46 edges and classified according to the $h$ values. The length of the perimeter amounts to the same as the number of external vertices, say $n_{\mathrm{e}}$. This number, being one of the invariants of a benzenoid, is closely related to the invariant $n_{\mathrm{i}}$. From the known connections between invariants of a benzenoid [35, 38] it is obtained

$$
n_{\mathrm{i}}=2 h-\left(n_{\mathrm{e}} / 2\right)+1 .
$$

Hence also the data of Stojmenović et al. [34] contain the information about the numbers of internal vertices. As such most of these data are entered into Table 8. The table would be too voluminous if all the available data [34] were included. They cover all benzenoids up to $n_{\mathrm{e}}=46$, which makes the highest entry of $h$ equal to 44 . Actually a unique benzenoid with $h=44$ and $n_{\mathrm{e}}=46$ is listed; it has 66 internal vertices $\left(n_{\mathrm{i}}=66\right)$.

The open spaces to the right and above the figures in Table 8 are equivalent to zeros. They reflect the fact that $n_{\mathrm{i}}$ has a maximal value for a given $h$. According to Harary and Harborth [5] this maximum is

$$
\left(n_{\mathrm{i}}\right)_{\max }=2 h+1-\left\{(12 h-3)^{1 / 2}\right\},
$$

where $\{x\}$ is used to denote the smallest integer greater than or equal to $x$. We also deduce straightforwardly that the length of the perimeter is bounded as

$$
2\left\{(12 h-3)^{1 / 2}\right\} \leqq n_{\mathrm{e}} \leqq 4 h+2 .
$$

As an example, the formulas give for $h=44$ : $\left(n_{\mathrm{i}}\right)_{\max }=66, \quad\left(n_{\mathrm{e}}\right)_{\min }=46$, both figures in consistence with the above quoted case.

\section{The ABCDEF Classification}

$\mathrm{He}$ and $\mathrm{He}[20,33]$ have classified the benzenoids and coronoids into the following six classes. A are the Kekuléans, $\mathrm{B}+\mathrm{C}$ cover the catacondensed benzenoid systems: $\mathrm{B}$ unbranched and $\mathrm{C}$ branched. $\mathrm{D}+\mathrm{F}$ cover the pericondensed benzenoids, $\mathrm{D}$ not possessing any end hexagon and $\mathrm{F}$ possessing at least one end hexagon, i.e. one with five free edges and manifested by a vertex of degree one in the dualist graph. The class $\mathrm{E}$ is coincident with the primitive coronoids. The rest of the coronoids come under $\mathrm{D}$ and $\mathrm{F}$ depending on whether they have not or have end hexagons, respectively. The classes D and $\mathrm{F}$ are separated into Kekuléans and non-Kekuléans. It is referred to Table 9 for enumeration results.

This classification is conveniently performed by means of (a) $\Delta$ values equal to $|U-D|$ and (b) $(U+D)$ values, where $U$ and $D$ are the respective numbers of upright and upset triangles in the 
Table 8. Numbers of benzenoids with different numbers of internal vertices, $n_{\mathrm{i}}$.

\begin{tabular}{|c|c|c|c|c|c|c|c|c|c|c|c|c|c|c|}
\hline$h$ & $n_{\mathrm{i}}=0 *$ & 1 & 2 & 3 & 4 & 5 & 6 & 7 & 8 & 9 & 10 & 11 & 12 & 13 \\
\hline 1 & 1 & & & & & & & & & & & & & \\
\hline 2 & 1 & & & & & & & & & & & & & \\
\hline 3 & 2 & $1^{\mathrm{a}}$ & & & & & & & & & & & & \\
\hline 4 & 5 & $1^{\mathrm{a}}$ & $1^{\mathrm{a}}$ & & & & & & & & & & & \\
\hline 5 & 12 & $6^{\mathrm{a}}$ & $3^{\mathrm{a}}$ & $1^{\mathrm{a}}$ & & & & & & & & & & \\
\hline 6 & 36 & $24^{\mathrm{a}}$ & $14^{\mathrm{a}}$ & $4^{\mathrm{a}}$ & $3^{\mathrm{a}}$ & & & & & & & & & \\
\hline 7 & 118 & $106^{\mathrm{a}}$ & $68^{a}$ & $25^{\mathrm{a}}$ & $10^{\mathrm{a}}$ & $3^{a}$ & $1^{\mathrm{a}}$ & & & & & & & \\
\hline 8 & 411 & $453^{a}$ & $329^{a}$ & $144^{\mathrm{a}}$ & $67^{\mathrm{a}}$ & $21^{\mathrm{a}}$ & $9^{a}$ & $1^{\mathrm{a}}$ & & & & & & \\
\hline 9 & 1489 & $1966^{\mathrm{a}}$ & $1601^{\mathrm{a}}$ & $825^{\mathrm{a}}$ & $396^{\mathrm{a}}$ & $154^{\mathrm{a}}$ & $55^{\mathrm{a}}$ & $15^{\mathrm{a}}$ & $4^{\mathrm{a}}$ & & & & & \\
\hline 10 & 5572 & $8395^{\mathrm{a}}$ & $7652^{\mathrm{a}}$ & $4518^{a}$ & $2340^{\mathrm{a}}$ & $1018^{\mathrm{a}}$ & $416^{\mathrm{a}}$ & $123^{\mathrm{a}}$ & $42^{\mathrm{a}}$ & $9^{\text {a }}$ & $1^{\mathrm{a}}$ & & & \\
\hline 11 & 21115 & $35885^{\mathrm{b}}$ & $36109^{b}$ & $24020^{\mathrm{b}}$ & $13415^{b}$ & $6405^{b}$ & $2811^{\mathrm{b}}$ & $1008^{b}$ & $333^{b}$ & $100^{b}$ & $26^{b}$ & $2^{b}$ & & \\
\hline 12 & $\dagger$ & $\dagger$ & $168318^{b}$ & $124119^{b}$ & $74985^{b}$ & $38727^{b}$ & $18306^{b}$ & $7375^{b}$ & $2713^{b}$ & $878^{b}$ & $279^{b}$ & $61^{\mathrm{b}}$ & $13^{b}$ & $1^{b}$ \\
\hline$h$ & $n_{\mathrm{i}}=4$ & & 6 & 7 & 8 & 9 & 10 & 11 & 12 & 13 & 13 & 14 & & 15 \\
\hline 13 & 408785 & $22683^{\circ}$ & $37 \quad 114326$ & 50405 & 20119 & 7253 & 2459 & 708 & 187 & 35 & 35 & 4 & & \\
\hline 14 & & $\dagger$ & $\dagger 691933$ & 328592 & 141268 & 55124 & 20321 & 6594 & 2001 & 533 & 33 & 120 & & 16 \\
\hline 15 & & $\dagger$ & $\dagger$ & $\dagger$ & 947291 & 395860 & 155656 & 55857 & 18396 & 5612 & & 1570 & & 347 \\
\hline 16 & & $\dagger$ & $\dagger$ & $\dagger$ & $\dagger$ & $\dagger$ & 1132642 & 436698 & 156434 & 51691 & 91 & 16234 & & 501 \\
\hline 17 & & $\dagger$ & t & $\dagger$ & $\dagger$ & $\dagger$ & $\dagger$ & $\dagger$ & 1236839 & 440491 & 91 & 48430 & & 166 \\
\hline 18 & & $\dagger$ & $\dagger$ & $\dagger$ & $\dagger$ & $\dagger$ & $\dagger$ & $t$ & $\dagger$ & & $\dagger 12$ & 62442 & 4244 & 429 \\
\hline$h$ & $n_{\mathrm{i}}=16$ & 17 & 18 & 19 & 20 & 21 & 22 & 23 & 24 & 25 & 26 & 27 & & 28 \\
\hline
\end{tabular}

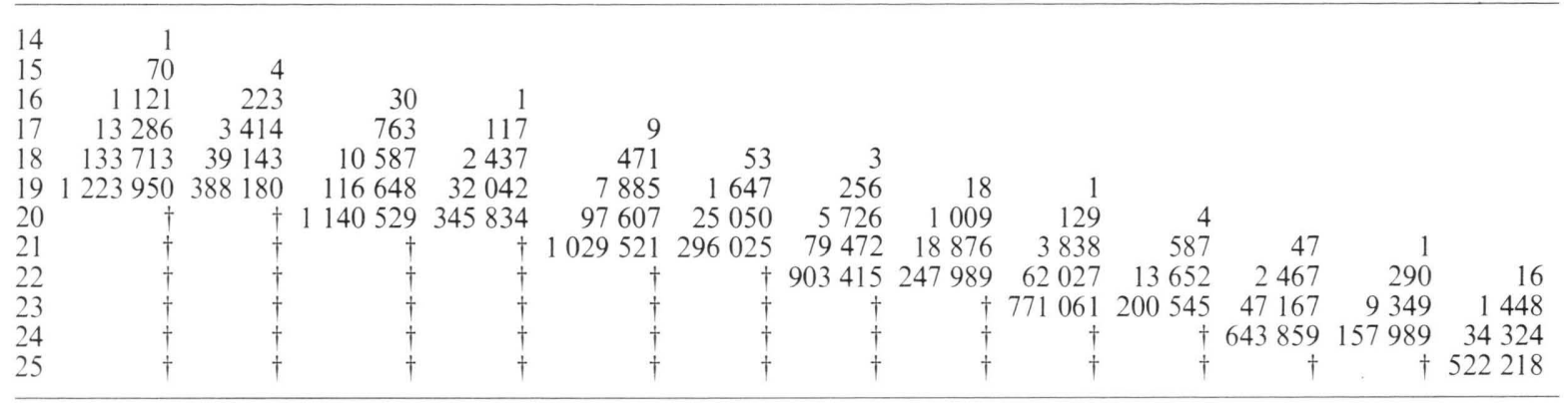

* Catacondensed benzenoids; see Table $1 .-{ }^{\dagger}$ Unknown.

a Knop, Szymanski, Jeričević, and Trinajstić [11].

b Stojmenović, Tošić, and Doroslovački [34]. All data for $h>10$ are taken from this reference.

Table 9. Numbers of benzenoids and coronoids (numbers in parentheses) according to the ABCDEF classification.

\begin{tabular}{|c|c|c|c|c|c|c|c|}
\hline \multirow[t]{2}{*}{$h$} & \multicolumn{5}{|c|}{ A Kekuléan } & \multicolumn{2}{|c|}{ Non-Kekuléan } \\
\hline & $\mathrm{B}^{*}$ & $\mathrm{C}^{*}$ & $\mathrm{D}$ & $E^{* *}$ & $\mathrm{~F}$ & $\mathrm{D}$ & $\mathrm{F}$ \\
\hline 1 & 1 & 0 & 0 & 0 & 0 & 0 & 0 \\
\hline 2 & 1 & 0 & 0 & 0 & 0 & 0 & 0 \\
\hline 3 & 2 & 0 & 0 & 0 & 0 & $1^{\mathrm{a}}$ & 0 \\
\hline 4 & 4 & 1 & $1^{\mathrm{a}}$ & 0 & 0 & $0^{\text {a }}$ & $1^{\mathrm{a}}$ \\
\hline 5 & 10 & 2 & $1^{\mathrm{a}}$ & 0 & $2^{\mathrm{a}}$ & $1^{\mathrm{a}}$ & $6^{\mathrm{a}}$ \\
\hline 6 & 24 & 12 & $3^{\mathrm{a}}$ & 0 & $12^{\mathrm{a}}$ & $3^{\mathrm{a}}$ & $27^{\mathrm{a}}$ \\
\hline 7 & 67 & 51 & $6^{\mathrm{a}}$ & 0 & $66^{\mathrm{a}}$ & $9^{\mathrm{a}}$ & $132^{\mathrm{a}}$ \\
\hline 8 & 182 & 229 & $22^{\mathrm{a}}$ & (1) & $331^{\mathrm{a}}$ & $27^{\mathrm{a}}$ & $644^{a}$ \\
\hline 9 & 520 & 969 & $60^{b}$ & (1) & $1674(2)$ & $117(2)$ & $3165^{b}$ \\
\hline 10 & 1474 & 4098 & $224(9)$ & (3) & $8311(12)$ & 437 (6) & $15542(13)$ \\
\hline 11 & 4248 & 16867 & $806(13)$ & (2) & $40958(113)$ & $1778(52)$ & $76572(103)$ \\
\hline
\end{tabular}

* See Table 1 (catacondensed); B unbranched, C branched.

** See Table 3 (primitive). $-{ }^{a} \mathrm{He}$ and $\mathrm{He}[20] .-{ }^{\mathrm{b}} \mathrm{He}$ and $\mathrm{He}[33]$. 
dualist graph, and (c) $V_{1}, V_{2}$ and $V_{3}$, designating numbers of vertices of the dualist graph with degree one, two and three, respectively.

These values are easily obtained from the $\mathrm{He}$ matrix [20]. It is noted that in the graph generation program of $\mathrm{He}$ and $\mathrm{He}[20]$, considering the connectivity of the graph and using the properties of the He-matrix, the coronoids are automatically included into the classification. In particular the He-matrix can be used to classify the systems according to $\Delta$ values. A He-matrix is also suited for the studies of the rotation and reflection transformations. Thus it may be used to determine the symmetry groups of the benzenoid and coronoid systems.

\section{Estimates for the Number of Benzenoids}

As the number $h$ of hexagons increases, the direct enumeration of benzenoids becomes extremely difficult and even with the use of the most powerful computing devices one cannot expect the solution of this task for the totality of benzenoids with, say, $h=20$ or $h=30$. Another approach to this problem would be the application of Pólya's theory, which provides general mathematical techniques for enumerations of combinatorial objects of various types [47]. Unfortunately, the enumeration of benzenoids by means of Pólya's method could not be realized until now and is considered as an open problem of combinatorics. From a mathematician's point of view, the enumeration of benzenoid systems is an unsolved problem.

If helicenes and other non-planar systems are not disregarded, then for large values of $h$ an exact asymptotic behaviour of the number of catacondensed benzenoids is known [3] and has the form

$$
N \approx a h^{p} b^{h},
$$

where $p, a$ and $b$ are specified constants. This result does not apply for catacondensed systems as defined in the present paper. Nevertheless, it has been attempted [27] to reproduce an approximate asymptotic behaviour of catacondensed benzenoids with helicenetype systems disregarded by the same mathematical form, but other values of the parameters $p, a$ and $b$. By a fitting procedure, using the known numbers for $h \leqq 11$, Gutman [27] determined $p=-5 / 4, a=0.049$ and $b=4.27$. In an analogous way he also determined a set of parameters, viz. $p=-3 / 2, a=0.045$
Table 10. Comparison between exact and estimated numbers of catacondensed benzenoids and all benzenoids.

\begin{tabular}{|c|c|c|c|c|}
\hline \multirow[t]{2}{*}{$h$} & \multicolumn{2}{|c|}{ Catacondensed benzenoids } & \multicolumn{2}{|c|}{ Total benzenoids } \\
\hline & Exact & Estimate $^{a}$ & Exact & Estimate \\
\hline 6 & 36 & 32 & 81 & 76 \\
\hline 7 & 118 & 111 & 331 & $\begin{array}{r}325 \\
+\quad 10\end{array}$ \\
\hline 8 & 411 & 402 & 1435 & $\begin{array}{r}1440 \\
\pm 40\end{array}$ \\
\hline 9 & 1489 & $\begin{array}{r}1480 \\
\pm 30\end{array}$ & 6505 & $\begin{array}{r}6510 \\
+180\end{array}$ \\
\hline 10 & 5572 & $\begin{array}{r}5550 \\
\pm 120\end{array}$ & 30086 & $\begin{array}{r}30000 \\
\pm 900\end{array}$ \\
\hline 11 & 21115 & $\begin{array}{r}21050 \\
\pm 500\end{array}$ & 141229 & $\begin{array}{r}140400 \\
\pm 4400\end{array}$ \\
\hline 12 & $\dagger$ & $\begin{array}{r}80600 \\
+2000\end{array}$ & $\dagger$ & $\begin{array}{r}666000 \\
\pm 22000\end{array}$ \\
\hline 13 & $\dagger$ & $\begin{array}{l}311000 \\
\pm 8000\end{array}$ & $\dagger$ & $\begin{array}{r}3190000 \\
\pm 110000\end{array}$ \\
\hline 14 & $\dagger$ & $\begin{array}{r}1212000 \\
\pm 32000\end{array}$ & $\dagger$ & $\begin{array}{r}15400000 \\
\pm 570000\end{array}$ \\
\hline 15 & $\dagger$ & $\begin{array}{r}4750000 \\
\pm 130000\end{array}$ & $\dagger$ & $\begin{array}{r}75000000 \\
\pm 2900000\end{array}$ \\
\hline
\end{tabular}

a The constants $a$ and $b$ (see the text for definitions) are assumed to have the values $0.049 \pm 0.0005$ and $4.27 \pm 0.005$, respectively. $-{ }^{\mathrm{b}} a=0.045 \pm 0.0005, b=5.4 \pm 0.01$

$\dagger$ Unknown.

and $b=5.4$, for the total number of benzenoids (both catacondensed and pericondensed). A corresponding analysis for normal benzenoids is due to Cyvin et al. [32].

In Table 10 the exact and estimated numbers of catacondensed benzenoids and benzenoids in total are given for $6 \leqq h \leqq 15$.

\section{Conclusion}

The present report does not imply an end to the enumeration and classification of polyhexes. On the contrary, the activity in this research area has apparently been intensivated during the last years, and not least during the preparation of this report. New results are to be awaited, further extensions to higher $h$ values on one hand and new types of classifications on the other.

\section{Acknowledgement}

Financial support to BNC from The Norwegian Research Council for Science and the Humanities is gratefully acknowledged. 
[1] D. A. Klarner, Fibonacci Quarterly 3,9 (1965).

[2] F. Harary, in: Graph Theory and Theoretical Physics (F. Harary, ed.). Academic Press, London 1967; p. 1.

[3] F. Harary and R. C. Read, Proc. Edinburgh Math. Soc. 17 (Ser. II), 1 (1970).

[4] W. F. Lunnon, in: Graph Theory and Computing (R. C. Read, ed.). Academic Press, New York 1972, p. 87.

[5] F. Harary and H. Harborth, J. Combinat. Inf. \& System Sci. 1, 1 (1976).

[6] A. T. Balaban and F. Harary, Tetrahedron 24, 2505 (1968).

[7] A. T. Balaban, Tetrahedron 25, 2949 (1969).

[8] A. T. Balaban, Match (Mülheim) 2, 51 (1976).

[9] K. Balasubramanian, J. J. Kaufman, W. S. Koski, and A. T. Balaban, J. Comput. Chem. 1, 149 (1980).

[10] J. R. Dias, J. Chem. Inf. Comput. Sci. 22, 15 (1982).

[11] J. V. Knop, K. Szymanski, Ž. Jeričević, and N. Trinajstić, J. Comput. Chem. 4, 23 (1983).

[12] N. Trinajstić, Ż. Jeričević, J. V. Knop, W. R. Müller, and K. Szymanski, Pure \& Appl. Chem. 55, 379 (1983).

[13] J. R. Dias, Can. J. Chem. 62, 2914 (1984)

[14] J. R. Dias, J. Chem. Inf. Comput. Sci. 24, 124 (1984).

[15] R. Doroslovački and R. Tošić, Rev. Res. Fac. Sci. Univ. Novi Sad, Math. Ser. 14, 201 (1984).

[16] J. V. Knop, K. Szymanski, Ž. Jeričević, and N. Trinajstić, Match (Mülheim) 16, 119 (1984).

[17] J. R. Dias, Accounts Chem. Res. 18, 241 (1985)

[18] J. R. Dias, J. Macromol. Sci. - Chem. A 22, 335 (1985).

[19] J. R. Dias, Nuov. J. Chim. 9, 125 (1985).

[20] W. He and W. He, Theor. Chim. Acta 68, 301 (1985).

[21] J. V. Knop, W. R. Müller, K. Szymanski, and N. Trinajstic, Computer Generation of Certain Classes of Molecules, Union of Chemists and Technologists of Croatia, Zagreb 1985.

[22] J. R. Dias, J. Mol. Struct. (Theochem.) 137, 9 (1986).

[23] R. Tošić, R. Doroslovački, and I. Gutman, Match (Mülheim) 19,219 (1986).

[24] S. J. Cyvin, Match (Mülheim) 20, 165 (1986).

[25] J. V. Knop, W. R. Müller, K. Szymanski, and N. Trinajstić, Match (Mülheim) 20,197 (1986).
[26] S. J. Cyvin and I. Gutman, Z. Naturforsch. 41 a, 1079 (1986).

[27] I. Gutman, Z. Naturforsch. 41 a, 1089 (1986)

[28] J. Brunvoll, B. N. Cyvin, and S. J. Cyvin, J. Chem. Inf. Comput. Sci. 27, 14 (1987).

[29] J. Brunvoll, S. J. Cyvin, and B. N. Cyvin, J. Comput. Chem. 8, 189 (1987)

[30] J. Cioslowski, J. Comput. Chem. (in press).

[31] B. N. Cyvin, J. Brunvoll, S. J. Cyvin, and I. Gutman, Match (Mülheim) 21, 301 (1986).

[32] S. J. Cyvin, J. Brunvoll, and B. N. Cyvin, Z. Naturforsch. 41 a, 1429 (1986).

[33] W. He and W. He, Tetrahedron 42, 5291 (1986).

[34] I. Stojmenović, R. Tošić, and R. Doroslovački, in: Graph Theory, Proceedings of the Sixth Yugoslav Seminar on Graph Theory Dubrovnik, April 18-19, 1985 (R. Tošić, D. Acketa, and V. Petrović, eds). University of Novi Sad, Novi Sad 1986, p. 189.

[35] I. Gutman, Bull. Soc. Chim. Beograd 47, 453 (1982).

[36] I. Gutman and O. E. Polanski, Mathematical Concepts in Organic Chemistry. Springer-Verlag, Berlin 1986.

[37] I. Gutman, Croat. Chem. Acta 46, 209 (1974).

[38] O. E. Polansky and D. H. Rouvray, Match (Mülheim) 2, 63 (1976)

[39] O. E. Polansky and D. H. Rouvray, Match (Mülheim) 3, 97 (1977)

[40] N. Trinajstić, Chemical Graph Theory, Vols. I, II, CRC Press, Boca Raton, Florida 1983.

[41] S. J. Cyvin, B. N. Cyvin, and I. Gutman, Z. Naturforsch. $\mathbf{4 0}$ a, 1253 (1985).

[42] S. J. Cyvin and I. Gutman, Comp. Maths. Appls. 12 B, 859 (1986).

[43] I. Gutman and S. J. Cyvin, J. Mol. Struct. (Theochem.) 138, 325 (1986)

[44] S. J. Cyvin and I. Gutman, J. Mol. Struct. (Theochem.) 150, 157 (1987).

[45] A. T. Balaban, Rev. Roum. Chim. 26, 407 (1981).

[46] A. T. Balaban, Tetrahedron 27,6115 (1971).

[47] F. Harary and E. P. Palmer, Graphical Enumeration, Academic Press, New York 1973. 